\title{
Growth Hormone Treatment at Nippon Medical School Chiba Hokusoh Hospital
}

\author{
Eri Kuramochi*, Kazuya Mae*, Yuuka Ohtomo*, \\ Reina Kamada*, Hanako Sugano-Tajima and Takeshi Asano \\ Department of Pediatrics, Nippon Medical School Chiba Hokusoh Hospital, Chiba, Japan
}

Background: Since 2002, the Department of Pediatrics of Nippon Medical School Chiba Hokusoh Hospital has offered educational activities for children with short stature. We analyzed outcomes of growth hormone $(\mathrm{GH})$ treatment for children with short stature treated at our hospital, particularly outcomes after the growth spurt.

Methods: We analyzed data from children aged 0 to 17 years who were treated with recombinant GH during the period from 2000 through 2016 and were followed for at least 2 years after the start of treatment.

Results: Among children with short stature, 85 had GH deficiency, 5 had Turner syndrome, 9 were small for gestational age, and 1 had Noonan syndrome. The outcomes of GH treatment was similar to those previously reported in Japan. Children with GH deficiency who started GH treatment before the growth spurt exhibited marked height catch-up until the second year, but the effect decreased after 3 years. The effect of treatment for GH deficiency that was started after the growth spurt continued for 4 to 5 years after the start of treatment.

Conclusions: Improvement in height standard deviation score was similar when treatment was started before and after the growth spurt. (J Nippon Med Sch 2021; 88: 39-44)

Key words: short stature, growth hormone deficiency, recombinant growth hormone treatment

\section{Introduction}

Growth hormone (GH) therapy, using a pituitary-derived GH preparation, was first approved in Japan in $1975^{1}$. However, the supply was low, and not all patients requiring $\mathrm{GH}$ treatment could be treated. Introduction of recombinant GH preparations, in the 1980s, allowed all patients to be treated ${ }^{2}$.

Medical treatment of growth hormone-deficient (GHD) short stature is often delayed because parents are unaware that their child has short stature, that GHD short stature is treatable, and that the period during which GH therapy can be given is limited ${ }^{3}$. Since 2002, the Department of Pediatrics of Nippon Medical School Chiba Hokusoh Hospital has offered educational activities for children with short stature and their families, and many children and adolescents with short stature seek treatment at our hospital. In addition, the families of such children often inquire about treatment options and outcomes, especially after the growth spurt. Therefore, we analyzed treatment outcomes, in relation to timing of GH treatment, for children who received GH treatment at the Department of Pediatrics, Nippon Medical School Chiba Hokusoh Hospital.

\section{Methods}

\section{Participants}

We analyzed treatment effects for children aged 0 to 17 years who were treated with recombinant growth hormone during the period from 2000 through 2016 and were followed for at least 2 years after the start of treat-

\footnotetext{
* These authors contributed equally.

Correspondence to Takeshi Asano, MD, Department of Pediatrics, Nippon Medical School Chiba Hokusoh Hospital, 1715

Kamagari, Inzai, Chiba 270-1694, Japan

E-mail: July1364@nms.ac.jp

https://doi.org/10.1272/jnms.JNMS.2021_88-103

Journal Website (https://www.nms.ac.jp/sh/jnms/)
} 
ment.

Criteria for Administering Growth Hormone Preparation $^{4-6}$

In brief, the diagnostic criteria for short stature with GHD are (1) bone age (under 17 years for boys; under 15 years for girls); (2) height growth (current height is short vs height at same sex and age [standard value, -2 SD or less] or, if height is within the normal range, growth rate is less than the standard growth rate [-1.5 SD] for 2 years or more vs growth rate for same age); (3) symptomatic hypoglycemia; (4) intracranial organic lesions or other defects in pituitary hormone secretion; and (5) GH secretion stimulation test yields a low GH peak value with insulin loading, arginine loading, L-DOPA loading, clonidine loading, glucagon loading, or a GHRP-2 loading test. GH level standards and measurements were in accordance with guidelines established by The Japanese Society for Pediatric Endocrinology $y^{7,8}$.

The diagnostic criteria for initiating treatment for Turner syndrome are (1) bone age less than 15 years; (2) height growth (current height is short vs height at same sex and age [standard value, -2 SD or less] or, if height is within the normal range, growth rate is less than standard growth rate [ $-1.5 \mathrm{SD}$ ] for 2 years or more vs growth rate at same age); (3) chromosomal analysis shows the basic karyotype with deletion of the distal part of the short arm of one $X$ chromosome (preferably in a chromosome analysis of $>20$ cells); and (4) physical characteristics indicate a female phenotype.

The diagnostic criteria for small for gestational age (SGA) are (1) calendar age of at least 3 years; (2) bone age under 17 years for males and under 15 years for females; (3) weight at birth and height both less than the standard 10th percentile equivalent for gestational age, and weight or height at birth less than 2 SD equivalent to gestational age; (4) height growth (current height is short [less than $-2.5 \mathrm{SD}$ ] vs height for same sex and age or, if height is within the normal range, growth rate is less than standard growth rate [0 SD] vs growth rate of same age); and (5) if the cause of postnatal growth disorder is not intrauterine growth retardation, GH treatment is not indicated.

The dose of growth hormone was $0.175 \mathrm{mg} / \mathrm{kg} /$ week for GHD, 0.23 to $0.47 \mathrm{mg} / \mathrm{kg} /$ week for SGA, $0.35 \mathrm{mg}$ / $\mathrm{kg} /$ week for Turner syndrome, and $0.23 \mathrm{mg} / \mathrm{kg} /$ week for Noonan syndrome ${ }^{9,10}$.

\section{Variables Measured}

The variables evaluated were sex, age at consultation, height standard deviation score $(\mathrm{SDS})^{11}$, insulin-like growth factor I (IGF-I) standard deviation ${ }^{12-15}$ at consultation, height SDS after treatment, hormone concentrations, biochemical test values considered to be related to growth, and severity classified by peak GH value on a GH secretion stimulation test. This study was approved (no. 588) by the Ethics Committee of Nippon Medical School Chiba Hokusoh Hospital.

\section{Statistical Analysis}

Statistical analysis was performed by using the MannWhitney U-test to determine the significance of differences between groups. The chi-square test for independence or Fisher exact probability test was used for comparisons within groups. The software package KaleidaGraph (Synergy Software, Reading, PA, USA) was used for correlation coefficient analysis.

\section{Results}

Causative Diseases and Number of Patients with Short Stature

The patients with short stature included 85 with GHD, 5 with Turner syndrome, 9 with SGA, and 1 with Noonan syndrome. Among the 85 patients with GHD, 1 patient had craniopharyngioma.

\section{GHD}

Eighty-five patients with GHD were treated. At the start of treatment, height SDS was $-2.4 \pm 0.57$, and age at the start of treatment was $9.2 \pm 2.92$ years. Average duration of treatment was $4.4 \pm 1.8$ years, final measured height was $149.0 \pm 14.3 \mathrm{~cm}$, and final measured height growth SDS was $1.22 \pm 0.80$.

\section{Age at Start of Treatment for GHD}

Age at the start of treatment for GHD is shown in Figure 1a, b. There was no significant difference in age between boys (average $9.0 \pm 0.0$ years, $n=53$ ) and girls (9.4 \pm 2.9 years, $n=32$ ). Age at the time of the growth spurt was defined as 11 years for boys and 9 years for girls ${ }^{16}$. Age at treatment start was more likely to be after the growth spurt in girls than in boys ( $p<0.001$, chi-square test; Fig. 1).

\section{Height SDS at the Start of Treatment}

Height SDS at the start of treatment was $-2.44 \pm 0.62$ for boys and $-2.44 \pm 0.50$ for girls. When height SDS before and after the growth spurt were compared, height SDS was $-2.47 \pm 0.62$ in boys before the growth spurt, $2.49 \pm 0.49$ in girls before the growth spurt, $-2.39 \pm 0.62$ in boys after the growth spurt, and $-2.42 \pm 0.51$ in girls after the growth spurt. There was no significant difference in height SDS before and after the growth spurt. 

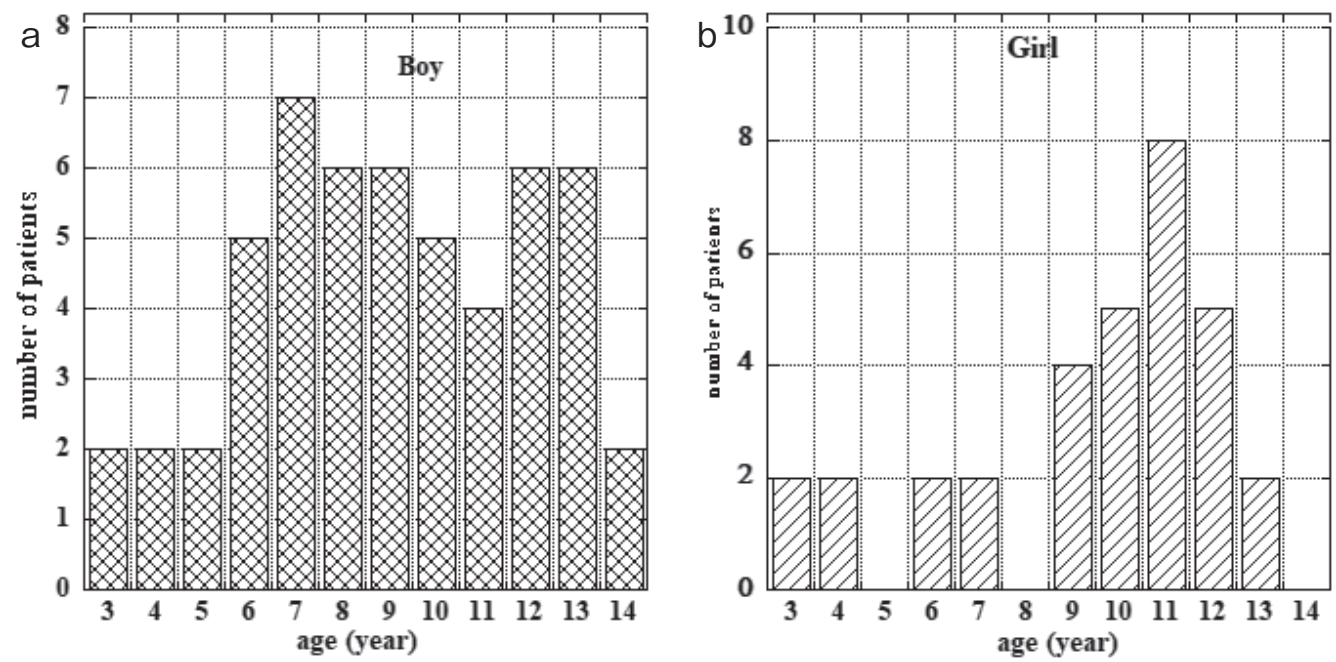

Fig. 1 Age distribution of children and adolescents with growth hormone deficiency. 1a: Boys: 1b: Girls

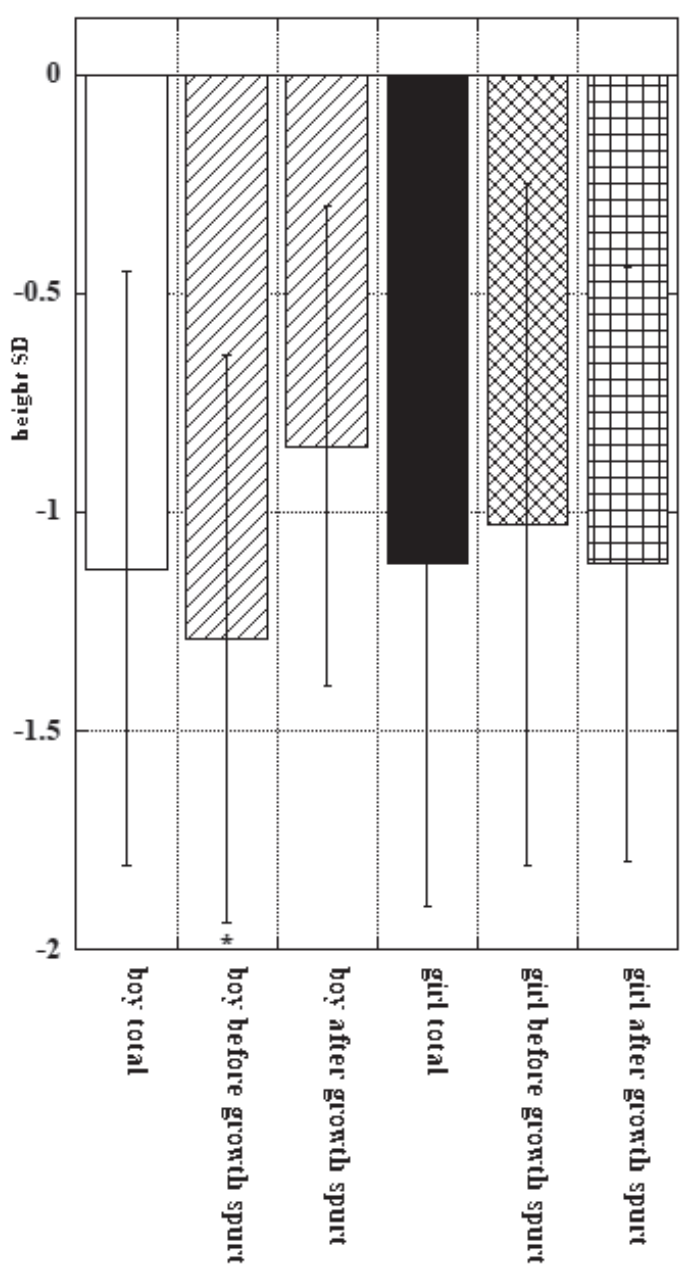

Fig. 2 Final measured height standard deviation score. Among boys, final measured height standard deviation score was significantly lower among those who started treatment before the growth spurt than for those who started treatment after the growth spurt $(\mathrm{p}=0.05)$.

\section{Final Measured Height SDS}

It is difficult to measure patients' final heights because they rarely come to our hospital after the end of $\mathrm{GH}$ treatment. Moreover, because patients receiving treatment were included in this study, SDS of the height at the final measurement was evaluated. There was no significant difference between boys $(-1.13 \pm 0.68)$ and girls $(-1.12 \pm$ 0.65) overall (Fig. 2). In a comparison of final measured height SDS before and after the growth spurt, height SDS was $-1.29 \pm 0.55$ at the start of treatment, before the growth spurt, in boys, $-0.85 \pm 0.78$ at the start of treatment, after the growth spurt, in boys, $-1.03 \pm 0.56$ at the start of treatment, before the growth spurt, in girls, and $1.12 \pm 0.68$ at the start of treatment, after the growth spurt, in girls. The final measured height SDS of boys who started treatment before the growth spurt was significantly lower than that of boys who started treatment after the growth spurt ( $\mathrm{p}=0.05)$.

\section{Treatment Duration}

Average treatment duration did not significantly differ between boys $(4.50 \pm 2.00$ years $)$ and girls (4.46 \pm 1.95 years). However, treatment duration significantly differed when treatment was started before and after the growth spurt in boys $(4.95 \pm 2.11$ years vs $3.54 \pm 1.26$ years, respectively; $\mathrm{p}=0.004)$ and girls $(6.01 \pm 1.83$ years vs 3.80 \pm 1.14 years; $\mathrm{p}=0.01$ ).

\section{Annual Height Growth}

Annual height growth was $6.98 \pm 1.50 \mathrm{~cm}$ per year for boys and $6.27 \pm 1.39 \mathrm{~cm}$ per year for girls and was significantly greater in boys $(\mathrm{p}=0.03)$. Boys grew $6.57 \pm$ $1.05 \mathrm{~cm}$ per year before the growth spurt and $7.77 \pm 1.91$ $\mathrm{cm}$ per year after the growth spurt $(\mathrm{p}=0.02)$; girls grew 
Table 1 Number of GHD patients in relation to GHD severity

\begin{tabular}{lcccc}
\hline \multicolumn{2}{c}{ Boys } & \multicolumn{2}{c}{ Girls } \\
\hline Disease severity & Before growth spurt & After growth spurt & Before growth spurt & After growth spurt \\
Mild & 19 & 12 & 6 & 20 \\
Moderate & 14 & 5 & 2 & 4 \\
Severe & 2 & 1 & 0 & 0 \\
\hline
\end{tabular}

The chi-square test showed no significant difference in the distributions of GHD severity before and after the growth spurt.

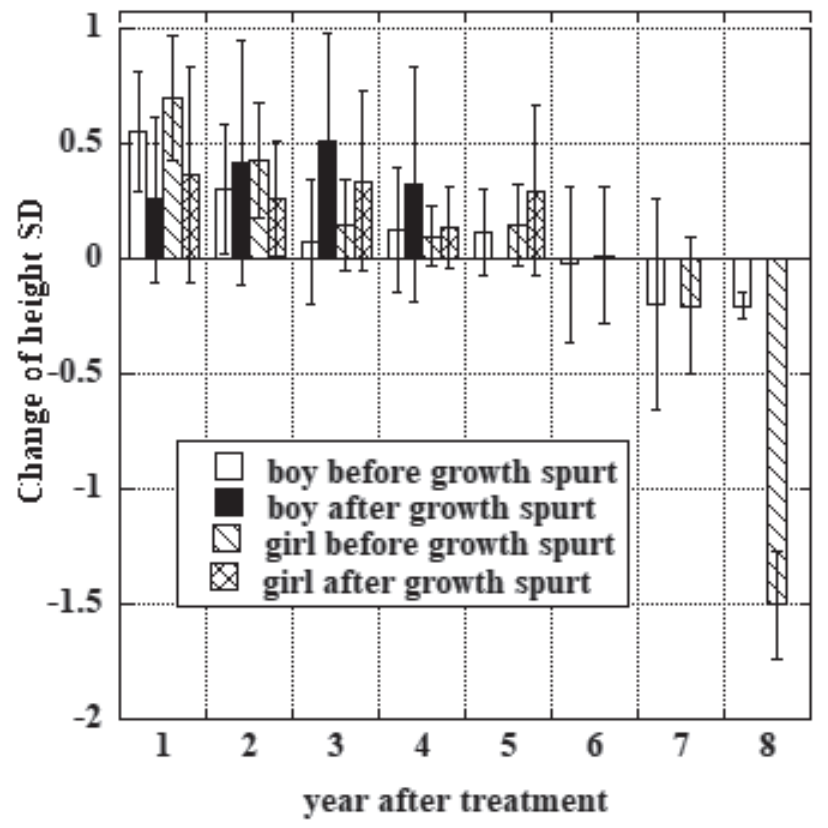

Fig. 3 Change in height standard deviation score (SDS). The extent of height growth was determined by examining yearly height SDS in relation to its change (height SDS - height SDS in previous year).

$6.75 \pm 0.92 \mathrm{~cm}$ per year before the growth spurt and $6.1 \pm$ $1.5 \mathrm{~cm}$ per year after the growth spurt. There was a significant difference in height growth between boys and girls who started treatment after the growth spurt ( $\mathrm{p}=$ 0.004).

Because height growth was clearly lower in boys that started treatment before the growth spurt than in the other groups, we examined if the difference was related to disease severity, as determined by the severity classification of the stress test ${ }^{11}$. The chi-square test showed no significant difference in the distributions of disease severity before and after the growth spurt (Table 1). Analysis of final measured height SDS in relation to disease severity in boys showed no significant difference. In addition, there was no significant difference in final measured height among children with mild, moderate, and severe disease, before or after the growth spurt.

\section{Change in Annual Height SDS After the Start of Treatment}

The extent of height growth was determined by examining yearly height SDS in relation to its change (height SDS - height SDS in previous year). That is, when height extends along with the standard growth curve, change in height SDS is zero. In GHD patients before the growth spurt, catch-up growth was substantial until the second year and decreased after 3 years, and boys exhibited the same growth as normal children after 6 years. Girls exhibited the same tendency after age 7 years (Fig. 3 ).

In contrast, among children with GHD who started treatment after the growth spurt, the treatment effect of catch-up growth persisted even after 4 to 5 years. Because the average duration of treatment for GHD patients who started treatment after the growth spurt was about 4 years, height did catch up, even when treatment was ended for financial reasons, such as ineligibility to receive medical support to continue GH treatment, because of the patient's age.

\section{Factors That Predicted Final Measured Height}

Analysis of factors that predicted final measured height included height SDS at treatment start and IGF-1 value before treatment. Starting height SDS was significantly positively correlated with final measured height ( $R$ $=0.46, \mathrm{p}<0.05$; Fig. 4). However, there was no significant correlation between pretreatment IGF-1 level and final measured height SDS (data not shown) or between IGF-1 (SD) and final measured height SDS (data not shown).

\section{Turner Syndrome}

Five patients were treated for Turner syndrome. At the start of treatment, height SDS was $-3.5 \pm 0.94$, and age at the start of treatment was $8.0 \pm 2.99$ years. Average duration of treatment was $7.6 \pm 2.3$ years, final measured height was $148.9 \pm 5.2 \mathrm{~cm}$, and final measured height growth SDS was $2.74 \pm 1.34$.

\section{SGA}

Nine patients were treated for SGA. Height SDS at the start of treatment was $-2.73 \pm 0.42$, age at the start of 


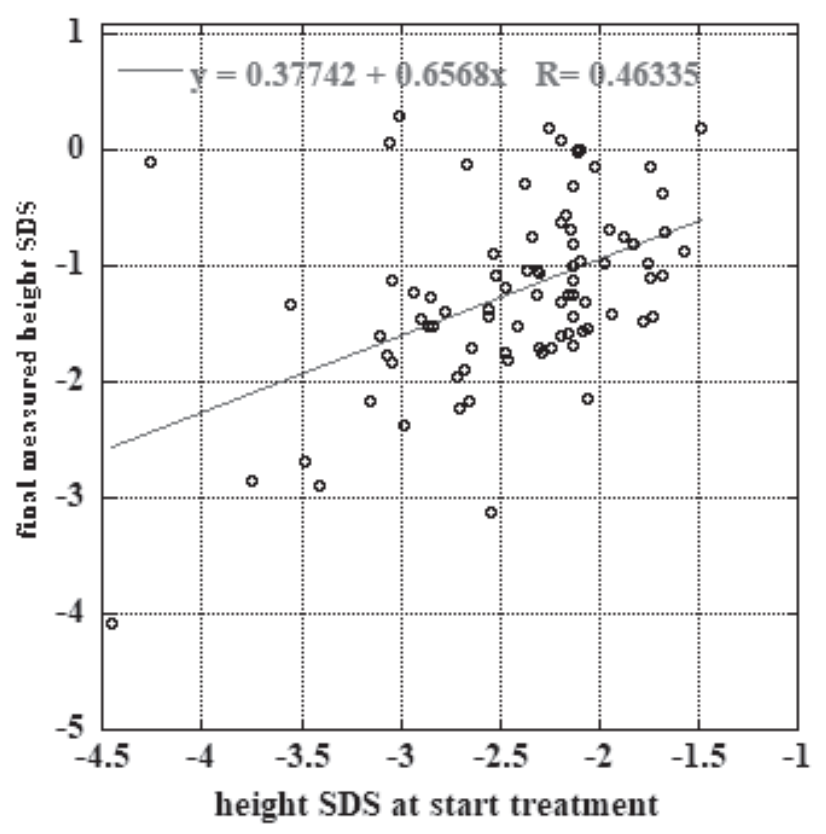

Fig. 4 Correlation between starting height standard deviation score (SDS) and final measured height. Starting height SDS was significantly positively correlated with final measured height $(\mathrm{R}=0.46, \mathrm{p}<0.05)$.

treatment was $8.50 \pm 3.96$ years, and average duration of treatment was $3.24 \pm 1.69$ years (at this writing). Final measured height was $138.4 \pm 13.1 \mathrm{~cm}$, final measured height growth SDS was $1.27 \pm 0.79$, and annual increase in height was $6.62 \pm 1.62 \mathrm{~cm}$. Growth in height was greater in children treated before the growth spurt.

\section{Discussion}

We investigated GH treatment over a period of 15 years in Nippon Medical School Chiba Hokusoh Hospital. The effects of GH treatment were similar to those previously reported in Japan ${ }^{17}$. Among boys, height was significantly shorter among those who started GH treatment before the growth spurt than among those who started GH treatment after the growth spurt. Among children with GHD who started GH treatment before the growth spurt, the degree of height catch-up was marked until the second year, decreased after 3 years, and was identical to normal growth after 6 years (for boys) and after 7 years (for girls). The treatment effect persisted-even 4 to 5 years after the start of GH therapy-among GHD patients that started treatment after the growth spurt. There was no significant difference in height SDS in relation to whether treatment was started before or after the growth spurt, except for boys who started treatment before the growth spurt. Finally, boys and girls who started treatment after the growth spurt had good height growth.
Treatment of GHD is believed to be more effective when patients are young. Some institutions do not actively test or treat children with short stature in upper elementary school grades and junior high school, perhaps because they believe that the treatment effects would be disappointing when compared with those for children beginning GH treatment before the growth spurt. We have been actively testing and treating patients with short stature, even those at older ages. The present analysis indicates that GH treatment yields similar improvement in height SDS when started before or after the growth spurt. Thus, if bone age satisfies the treatment criteria, active evaluation and treatment of short stature are not futile, even when a child or adolescent might be regarded as too old to benefit.

Acknowledgement: This study was partially supported by the Student Educational Program for Clinical Research of Nippon Medical School.

Conflict of Interest: No financial interests/relationships to declare.

\section{References}

1. Hibi I, Tanaka T. Final height of patients with idiopathic growth hormone deficiency after long-term growth hormone treatment. Committee for Treatment of Growth Hormone Deficient Children, Growth Science Foundation, Japan. Acta Endocrinol (Copenh). 1989 Apr;120(4):409-15.

2. Yokoya S, Tanaka T. The History of Growth Hormone Treatment for GHD in Japan. Pediatr Endocrinol Rev. 2017 Mar;14 Suppl 1(Suppl 1):201-8.

3. Asano T. Teishinchou wo shuso ni jusinn sita kanji/kazoku no jusin no Kikkake ni kannsuru anke-to [Clue of Referral to Hospital Because of Short Stature]. Japanese Journal of Child Health. 2016;75(6):828-32.

4. Information Center for Specific Pediatric Chronic Disease, Japan. [Growth hormone deficiency] [Internet]. [cited 2020 Feb 6]. Available from: https://www.shouman.jp/di sease/instructions/05_04_005/

5. Information Center for Specific Pediatric Chronic Disease, Japan. [Turner syndrome] [Internet]. [cited $2020 \mathrm{Feb} 6$ ]. Available from: https://www.shouman.jp/disease/detail s/05_41_088/

6. Tanaka T, Yokoya S, Nishi Y, et al. SGAsei teisinchoushou ni okeru GHchiryou gaidorain [Treatment guideline for SGA short stature]. Jpn J Pediatr Soc. 2007;111(4):641-6.

7. Tanaka T, Shimazu A. Seichou horumon sokuteichi no hoseisiki ni tsuiteno oshirase [Notice for correction of GH value measurement]. 9 [Internet]. [cited 2020 Feb 6]. Available from: http://www.fgs.or.jp/pdf/01_hormone_b usiness_promotion/03_related_research/02_gh/070_notic e_27_9.pdf

8. The Foundation for Growth Science. Seichouhorumon sokuteihou no hyoujunka no keii [Explanation of standardization for method of GH value] [Internet]. [cited 2020 Feb 6]. Available from: http://www.fgs.or.jp/busine ss/growth_hormone/research_study/gh/ 
9. The Japanese Society for Pediatric Endocrinology. Seichouhorumon no tekiseisiyou ni kansuru kenkai [Opinion on proper use of recombinant GH] [Internet]. [cited 2020 Feb 6]. Available from: http://jspe.umin.jp/medical/gh.ht $\mathrm{ml}$

10. The Japanese Society for Pediatric Endocrinology. Noonan shoukougun ni okeru teishinchou ni taisuru GHchiryou no jisshijou no chuuiten [Notice for practical use of GH therapy on Noonan syndrome with short starture] [Internet]. [cited 2020 Feb 6]. Available from: http://jspe.umin. $\mathrm{jp} /$ medical/files/guide20171130.pdf

11. Isojima $T$, Hasegawa $T$, Yokoya $S$, Tanaka $T$. The response to growth hormone treatment in prepubertal children with growth hormone deficiency in Japan: Comparing three consecutive years of treatment data of The Foundation for Growth Science in Japan between the 1990s and 2000s. Endocrine J. 2017;64(9):851-8.

12. SRL General guide. IGF-1 [value for IGF-1] [Internet]. [cited 2020 Feb 6]. Available from: https://test-guide.srl.i nfo/hachioji/test/detail/003852102

13. Shimazu A. IGF-1 kijunchi ichiranhyou danji [Table of normal range of IGF-1. Boy] [Internet]. [cited $2020 \mathrm{Feb}$ 6]. Available from: https://ghw.pfizer.co.jp/adult/inform ation/igf-i/pdf/IGF-Iman.pdf

14. Shimazu A. IGF-1 kijunchi ichiranhyou joji [Table of normal range of IGF-1. Girl] [Internet]. [cited 2020 Feb 6]. Available from: https://ghw.pfizer.co.jp/adult/informatio
n/igf-i/pdf/IGF-Iwoman.pdf

15. Pfizer. Seijin no seichouhorumon bunpitsufuzenshou [IGF-1 value for adult GHD] [Internet]. [cited $2020 \mathrm{Feb}$ 6]. Available from: https://ghw.pfizer.co.jp/adult/inform ation/igf-i/index.html

16. Yoshii K, Tanaka T. Establishment of a longitudinal growth chart corresponding to pubertal timing. Clin Pediatr Endocrinol. 2018;27(4):215-24.

17. Ogawa M, Nose O, Okada T, et al; Study Group of Outpatient Clinics on Short Stature. Improvement of Adult Height in GH treated Idiopathic Growth Hormone Deficiency. Jpn J Pediatr Soc. 2012;116:979-84.

(Received, October 1, 2019)

(Accepted, February 26, 2020)

(J-STAGE Advance Publication, May 30, 2020)

Journal of Nippon Medical School has adopted the Creative Commons Attribution-NonCommercial-NoDerivatives 4.0 International License (https://creativecommons.org/licenses/by-nc-nd/4.0/) for this article. The Medical Association of Nippon Medical School remains the copyright holder of all articles. Anyone may download, reuse, copy, reprint, or distribute articles for non-profit purposes under this license, on condition that the authors of the articles are properly credited. 